\title{
El legado educativo de la Segunda República
}

\section{Antecedentes históricos}

Hace ya mucho tiempo que, entre nosotros, decir república es decir educación. Así se ha venido sintiendo y así lo sentimos hoy. República es sinónimo de educación, sinónimo de cultura, sinónimo de progreso. En realidad, la historia de la educación pública contemporánea va siempre íntimamente unida a la historia de la República como modelo de Estado. Aunque no puede establecerse una correlación unívoca y determinante entre 'sistema de educación pública' y 'sistema político republicano', no cabe duda que los momentos mejores y más felices de nuestras sociedades contemporáneas — particularmente en Europa y en todo lo que concierne a la educación pública - han sido siempre momentos republicanos.

Así había sido ya en la Antigüedad clásica, cuando Platón establecía hace ya dos mil quinientos años los principios básicos y teóricos de la educación pública en su obra inmortal titulada precisamente así: La República. Platón será el primero en entender el carácter reproductor de la educación y el primero en concluir que la educación actúa como principal elemento perpetuador de determinados valores e intereses sociales. A partir de entonces ya podrá hablarse sin equívocos de la educación como una de las tareas primordiales del Estado (aunque la estructura del Estado, tal y como hoy la concebimos, no aparezca hasta muchos siglos después).

Por su parte (y también en aquella época), Aristóteles diseña a grandes rasgos lo que debe ser el 'curriculum' en la Grecia clásica y las características del sistema educativo en la Ciudad-Estado. Y lo hace en su célebre obra titulada Política, con lo que subraya de una manera definitiva el carácter eminentemente político de la educación y extrae las primeras conclusiones sociológicas contundentes de la división social del trabajo. En algunos capítulos de esa obra, Aristóteles aborda las diferencias sustanciales en aquella sociedad entre los propietarios de esclavos y los esclavos mismos, entre los artesanos y los hombres libres, entre las disciplinas 'útiles' y las disciplinas 'sublimes', entre el 'ocio' de los hombres libres y el 'negocio' de los que ganan el pan con sus manos - como se diría tiempo después-. Como puede verse, resulta relativamente sencillo aplicar las teorías platónicas y aristotélicas a los tiempos actuales...

Y si los orígenes 'teóricos' de la educación pública están en la Grecia clásica, los orígenes 'institucionales' estarán, en Europa occidental, en los establecimientos eclesiásticos medievales —como dice Émile Durkheim-. Es aquí donde la educación se convierte en 'sistema' propiamente dicho, aunque no se trate en este caso de un sistema al servicio del 
Estado, sino de un sistema al servicio de la superestructura dominante en aquel entonces, que no era otra sino la Iglesia.

Pero los orígenes 'textuales' que darían lugar al nacimiento de la educación pública de nuestro tiempo, aparecerán en el proceso revolucionario más completo de la época contemporánea: la Revolución Francesa de 1789, particularmente en las teorías de los ilustrados que la inspiraron (y en especial en algunos textos de Diderot, Helvétius y, sobre todo, de Rousseau) y explícitamente en los famosos Rapports revolucionarios. Con un paradigma indiscutible: el Rapport o Informe de Condorcet, de 1792.

Vendría después la larga lucha del siglo XIX europeo por la generalización y universalización de la escuela 'gratuita', 'obligatoria' y 'laica'. Y en ese contexto socioeducativo emergería con fuerza a principios del siglo XX la llamada 'escuela unificada' o 'escuela única', que constituiría el núcleo esencial de los movimientos de renovación pedagógica y el gran boom de la educación republicana de los años 30, ya en pleno siglo XX. A todo eso habría que añadir los efectos de todas las experiencias emanadas de la Revolución de Octubre de 1917 en Rusia, así como las consecuencias políticas, culturales y educativas de la Revolución China de 1949, que darían lugar a un vuelco en la geopolítica asiática y planetaria, o la Revolución Cubana de 1959, que generaría un buen número de movimientos sociales en América Latina.

\section{Una educación republicana}

El 14 de abril de 1931 provoca en los pueblos de España una quiebra social y política irreversible. A partir de ese día existirá ya para siempre entre nosotros la conciencia social de que el Antiguo Régimen ha caído. Los pueblos de España están dispuestos a no volver a la servidumbre nunca más. Por eso la Segunda República simboliza la modernización y la ruptura por excelencia. Modernización política y ruptura con el Antiguo Régimen y con el tardofeudalismo. Modernización económica que quedaría truncada por la resaca de la crisis mundial de 1929. Y modernización educativa y ruptura pedagógica con el monopolio que en el mundo de la enseñanza ejercía la Iglesia. "España ha dejado de ser católica", diría con alivio Manuel Azaña. La separación entre la Iglesia y el Estado que Francia, por ejemplo, había materializado en 1881 con las Leyes Férry sobre la escuela gratuita, obligatoria y laica, se daba en España, con la Segunda República, sólo en el papel. Hoy podríamos decir que aquellos polvos trajeron estos lodos...

Pero la línea a seguir estaba marcada. Las tareas estaban bien delimitadas. El trabajo durante aquellos años de república y guerra civil fue intenso y profundo. El sistema educativo republicano prendió en la conciencia de todas las gentes. Por eso el legado educativo republicano sigue estando vivo. Si el pasado es el único referente para construir nuestro futuro, no cabe duda que nuestro mejor pasado es aquel pasado republicano tan añorado, tan querido y tan vulnerado. Porque el torrente pedagógico republicano siguió corriendo como un río subterráneo y clandestino, mientras vivíamos la pesadilla de aquellos años duros y sórdidos de la dictadura franquista. 
Entre los grandes problemas abordados por la República en su primer bienio, el de la escuela se encuentra sin duda en lugar especialmente destacado. Hoy más que nunca podemos afirmar que, entre 1931 y 1936, la historia conoció no sólo una 'República de trabajadores de todas las clases', tal y como rezaba su Constitución y sobre la que ironizaba llya Ehremburg en un libro muy conocido, sino una auténtica República de 'maestros y trabajadores' que laboraron durante cinco años de una manera entusiasta y denodada. Por eso la guerra civil de 1936-39 fue el castigo que les impusieron los terratenientes, una parte de las Fuerzas Armadas y casi todo el clero. Fue una guerra de maestros contra curas, como dice Thomas. Y fueron los maestros y los trabajadores los que fueron atacados, fusilados, paseados, humillados y ofendidos.

Lo cierto es que el sistema educativo republicano iba a ser reestructurado de arriba abajo. La educación sufrió un cambio radical en sus planteamientos, tanto en extensión como en profundidad, tanto en términos de 'escuela única' como en términos de 'escuela activa', podríamos decir. La famosa cuatrimembración pedagógica republicana de una escuela única, activa, pública y laica iniciaba su andadura. Una escuela única y no dividida. Una escuela activa y no pasiva. Una escuela pública y no privada. Y una escuela laica y no confesional. Ese era el objetivo.

Y todo ello a partir del debate constitucional. Por esa razón José Bullejos, un clásico de la historiografía republicana, pudo decir en su obra España en la IIª República: "El Gobierno provisional apreció con atinado criterio la magnitud de la trascendental obra que iba a emprender y por eso llevó al Ministerio de Instrucción Pública a un grupo de hombres -Marcelino Domingo, Fernando de los Ríos, Domingo Barnés, Rodolfo Llopis y otros- que se inspiraban en las formas más modernas y progresistas del pensamiento pedagógico. Discípulos todos de Giner de los Ríos y Bartolomé Cossío, aunaban el ideal de estos grandes maestros con el sentido humanista del socialismo".

Con la IIํㅡ República la educación pasa a ser definitivamente una cuestión fundamental del Estado, tal y como querían los clásicos. El viejo problema que se debate en Europa durante el siglo XIX, se prolonga aquí en España en el XX. El régimen republicano decide sobre esta cuestión en abierta pugna con intereses privados, principalmente eclesiásticos. La educación estatal es para la República no sólo un asunto de Estado sino también un asunto 'de urgencia'.

En sus reiteradas formulaciones políticas de principios, los hombres del nuevo Estado saben que no puede haber reforma política si no va acompañada de una reforma educativa. 0 , como dice Rodolfo Llopis en un lenguaje más radical, "no hay revolución política sin revolución educativa". En su obra La revolución en la escuela afirma: "En todas partes, la escuela ha sido el arma ideológica de la revolución. Por eso no hay revolución que no lleve en sus entrañas una reforma pedagógica". Y por eso también, "todo revolucionario es, en el fondo, un maestro y todo educador auténtico tiene espíritu revolucionario", concluye Llopis.

El período decisivo para acelerar el cambio educativo republicano fue sin duda el primer bienio. Observándolo de cerca, podemos conocer los distintos pasos de la reforma 
educativa: en las Cortes y en el Ministerio, en la base y en la cúspide, en las nacionalidades y en el Estado, en los partidos y en otras instituciones. En fin, en los distintos niveles del sistema educativo, particularmente en la primaria. La República hará un esfuerzo notable para rescatar al pueblo de las garras del analfabetismo y de la ignorancia.

\section{Sobre la preparación del profesorado}

Lorenzo Luzuriaga Medina (1889-1959), un discípulo de Giner y Ortega y un hombre del partido socialista (ejemplo, pues, de la estrecha relación existente entre institucionistas y socialistas como agentes clave de la modernización educativa), es quizá el pedagogo de aquel tiempo que recoge con más detalle el perfil que, en su opinión, debe tener un maestro, un profesor.

El pedagogo manchego parte del supuesto de que sin reformadores no hay reforma posible. Por eso pone siempre muchísimo cuidado en todo lo referente a la formación del profesorado, muy en la línea de las preocupaciones institucionistas, por cierto. Ya en 1918 había publicado un libro con un título así: La preparación de los maestros. Y en 1920 publicará, en su página de Pedagogía del diario El Sol, un artículo sobre la necesidad de la preparación universitaria del Magisterio. Más: en mayo de 1931 aparecerá en la Revista de Pedagogía, que él dirigía, un artículo desbordante de pasión republicana: "Al servicio de la República: llamada al Magisterio", en el que trata de definir la conjunción que debe darse entre los aspectos técnicos y los aspectos políticos en la formación y en las actitudes del profesorado. En ese trabajo tan coyuntural dice por ejemplo: "Estamos ante un proceso profundo. No basta con la simple adhesión... Hay que educar republicanamente... Los maestros serán ejes principales de nuestra República".

El movimiento de renovación pedagógica de la 'escuela nueva' tomó diversas medidas que trataban de aclarar las finalidades nuevas de la educación renovada en todo lo que se relacionaba con la preparación de los maestros. Se trataba igualmente de resaltar los principales elementos que incidían en el hecho educativo (descubrimientos sociológicos y psicológicos, hallazgos históricos, etc.). Y se trataba también de inventariar los obstáculos que se interponían en este camino, así como de recalcar la necesidad de unos estudios cada vez más cualificados para los futuros miembros del Magisterio.

Los teóricos de la 'educación nueva' — maestros, inspectores, filósofos o psicólogostomaron la preparación del Magisterio como una condición indispensable de la reforma. Más aún: una de las facetas de la renovación educativa era la renovación de los educadores. Renovación técnica y cultural y también política e ideológica. La educación nueva pretendía modificar radicalmente no sólo la actitud profesional de los maestros sino su misma concepción del mundo. La mayoritariamente entusiasta participación de los maestros y sus ansias renovadoras posibilitaron los éxitos de la reforma. De los maestros y de gran número de intelectuales, habría que añadir (las Misiones Pedagógicas son un magnífico ejemplo).

La preparación de los profesores debe estar en función de las necesidades evolutivas del educando, pero requerirá idéntico nivel de conocimientos (aunque de distinto signo y contenido) para todas las edades. La discriminación se consideraba el fruto de circunstan- 
cias históricas que ya no tenían razón de ser. La equiparación debía ser, pues, pedagógica, social y económica. De este modo, la conjunción de la 'precisión técnica' y la 'precisión política' —utilizando la conocida expresión orteguiana - queda nítidamente recogida en diversos escritos publicísticos y programáticos de Lorenzo Luzuriaga que se convertirían, en muchos casos, en un modelo a seguir.

\section{Ideas pedagógicas reformadoras}

Tal es el caso de un opúsculo de título enormemente significativo: Ideas para una reforma constitucional de la educación pública, que aparecerá ya en abril de 1931. Su título mismo ya era una declaración de intenciones y se inscribía claramente en el debate constitucional. Será el primer intento serio de implantar en la España republicana un 'sistema de educación pública estatal'. Las Ideas de Luzuriaga eran un auténtico manifiesto pedagógico republicano que pretendía sentar las bases para una muy deseada Ley de Educación que la República no tuvo tiempo de promulgar. En aquella vertiginosa sucesión de acontecimientos políticos y sociales de todas clases que fueron surgiendo entre 1931 y 1936, no hubo ni un momento de respiro para echar a andar una ley tan necesaria. $Y$ habría que esperar ja 1970! para que la Ley General de Educación o Ley Villar (una ley ya más fuera que dentro del franquismo) diera por finiquitada la antediluviana Ley Moyano de 1857.

Esas Ideas que apuntaban a una reforma de la educación pública que pudiese ser acogida y recogida por la Constitución republicana, son una apretada síntesis en 13 puntos que resume el estado de la cuestión educativa y los proyectos pedagógicos más avanzados de aquel momento. Así, en el primero de ellos, se dice por ejemplo: "La educación, en todos sus grados y manifestaciones, es una función eminentemente pública. El Estado, como representante máximo de la vida nacional, es el llamado a realizarla. Corresponde, pues, al Parlamento la legislación de la enseñanza, y a los órganos y funcionarios del Estado su dirección, inspección y administración".

Se trata, como podemos observar, de afirmaciones diáfanas y sin paliativos. En el punto 5 se dice: "La educación pública ha de tener en cuenta sólo las capacidades y aptitudes del ser a educar". Y se extiende después en todo tipo de consideraciones socioeconómicas para que no se pierda ningún talento. Y todo eso — recuérdese- en aquella España eminentemente agraria y pobre de los años 30 . ¡Qué decir ahora de todo eso en este mundo de macroeconómica abundancia y del más disparatado despilfarro!

Como ejemplo de vanguardismo pedagógico y de la vigencia de aquellos planteamientos hay que señalar los puntos 6 y 12. En el punto 6 se aborda la cuestión tan bien estudiada, por otra parte, por José Castillejo en su libro Guerra de ideas en España, y tan debatida y matizada por los hombres de la Institución Libre de Enseñanza, sobre la necesidad de la fusión de la primaria y la secundaria, es decir, sobre la gratuidad y la obligatoriedad escolar desde los tres hasta los dieciocho años. Estamos hablando, naturalmente, de un pensamiento pedagógico audaz y vanguardista cien por cien, que sienta ya las bases inamovibles de lo que serán las enseñanzas comprensivas y la escuela democrática y antifascista. 
Y en el punto 12 se recogen ja comienzos de los años 30 ! muchas de las reivindicaciones ide ahora mismo! en lo que se refiere al cuerpo único de enseñantes, a la carrera del personal docente e investigador universitario que se está modificando en ese sentido con la remodelación de la LOU jen 2007! o a la cuestión del cambio de grado para el personal docente y que hoy denominamos cambio de nivel. Audacias pedagógicas todas ellas que deberían servir de ejemplo para la más completa modernización y dinamización de nuestro sistema educativo actual.

Estas y otras muchas cosas son las que pueden decirse hoy mismo, en los primeros meses del 2008, sobre el legado educativo de la Segunda República.

(Publicado en Cuadernos de Pedagogía, núm. 378, 2008, páxs. 78-81.) 